\title{
C5a receptor expression is associated with poor prognosis in urothelial cell carcinoma patients treated with radical cystectomy or nephroureterectomy
}

\author{
YOSHIHIRO WADA ${ }^{1 *}$, YOSHIHIRO MAEDA ${ }^{1 *}$, TATSUKO KUBO $^{2}$, \\ $\mathrm{KEN} \mathrm{KIKUCHI}^{3}$, MASATOSHI ETO ${ }^{1}$ and TAKAHISA IMAMURA ${ }^{2}$ \\ Departments of ${ }^{1}$ Urology and ${ }^{2}$ Molecular Pathology, Faculty of Life Sciences, Kumamoto University; \\ ${ }^{3}$ Medical Quality Management Center, Kumamoto University Hospital, Kumamoto 860-8556, Japan
}

Received April 23, 2015; Accepted July 1, 2016

DOI: $10.3892 / 01.2016 .5137$

\begin{abstract}
Patients with aggressive urothelial cell carcinoma (UCC) that undergo radical cystectomy or nephroureterectomy exhibit markedly high rates of disease recurrence and mortality. To select appropriate adjuvant thxerapies in addition to radical surgery, the identification of predictive prognostic markers for UCC patients is required. The aim of the present study was to identify such markers, by evaluating the association of UCC complement component 5 (C5) fragment a (C5a) receptor $(\mathrm{C} 5 \mathrm{aR})$ expression, detected using immunohistochemistry, with clinicopathological parameters and survival outcomes of UCC patients. The results revealed that C5aR was expressed in cancer cells, particularly at the invasive front, but not in noncancerous urothelial cells or adjacent cells. The UCC C5aR-positive rate of patients treated with radical surgeries was $73 \%(38 / 52)$ and the rate was $83 \%(20 / 24)$ at stages I-II of disease. No correlation between C5aR expression and any of clinicopathological parameters, which included gender, tumor location, World Health Organization grade, T stage, vessel invasion and stage of disease, was identified. However, univariate and multivariate analyses revealed that C5aR-positive UCC patients exhibited significantly lower overall survival rates [hazard ratio (HR), 3.14; 95\% confidence interval (CI), 1.03-9.60; $\mathrm{P}=0.035$ and $\mathrm{HR}, 3.92 ; 95 \% \mathrm{CI}, 1.15-13.4$; $\mathrm{P}=0.029$, respectively] and 5-year survival rates (0.42 vs. 0.83 ) compared with C5aR-negative UCC patients. Furthermore, 5-year survival and disease-specific survival rates were lower in patients with C5aR-positive UCC (0.51; 95\% CI, 0.30-0.71)
\end{abstract}

Correspondence to: Dr Takahisa Imamura, Department of Molecular Pathology, Faculty of Life Sciences, Kumamoto University, 1-1-1 Honjo, Kumamoto 860-8556, Japan

E-mail: taka@kumamoto-u.ac.jp

*Contributed equally

Key words: C5a receptor, urothelial cancer, prognosis, survival, radical surgery than patients with C5aR-negative UCC $(0.83 ; 95 \% \mathrm{CI}$, 0.62-1.00). These results indicate that UCC C5aR expression is predictive of poor patient outcomes and thus may lead to the appropriate selection of adjuvant therapies at earlier UCC stages, which could improve patient prognosis.

\section{Introduction}

Urothelial cell carcinoma (UCC) is one of the most common types of cancer in the USA, accounting for $\sim 4.5 \%$ of all newly diagnosed cancer cases and $2.8 \%$ of all cancer-associated mortalities in 2013 (1). In the USA, the most common site of UCC is the bladder, and bladder UCC is the fourth most common type of cancer and the sixth leading cause of cancer-associated mortality in males (1). Bladder UCC may be classified into two subtypes at diagnosis, non-muscle and muscle-invasive, which exhibit distinct clinical features (2). The non-muscle-invasive subtype commonly recurs in the bladder cavity and accounts for $70-80 \%$ of cases of bladder UCC, with muscle invasion present in only $10-20 \%$ of cases. The 5 -year survival rate of the non-muscle-invasive subtype of UCC is $>90 \%$. By contrast, muscle-invasive bladder UCC, which accounts for $20 \%$ of bladder UCC cases, exhibits a poor prognosis with a 5-year survival rate of $<50 \%$. Carcinoma in situ (CIS), which is classified into the non-muscle invasive aggressive subtype, is localized to the epithelium and exhibits invasive and metastatic potential. In patients with aggressive bladder UCC (muscle invasive UCC and CIS) without lymph nodes or distant metastasis, the standard and most effective treatment is total resection of the bladder and urethra, which includes the prostate in male patients. However, $\leq 50 \%$ of patients who undergo total cystectomy exhibit recurrence and develop distant metastases (3-5). Aggressive UCC with malignant potential may also originate from the upper urinary tract, renal calyx, renal pelvis and ureter (6). In patients with UCC of the upper urinary tract without lymph node or distant metastasis, the most effective treatment is total resection of the diseased section of the upper urinary tract, including the kidney, ureter and a section of the bladder (nephroureterectomy); however, $40 \%$ of UCC patients that undergo total nephroureterectomy have succumbed to the disease 5 years after surgery (7). In general, patients with muscle invasive bladder UCC, CIS of 
the lower urinary tract and UCC of the upper urinary tract are at high risk of recurrence, metastases and mortality even after radical surgery $(8,9)$. Therefore, to improve prognosis of the patients with aggressive UCC, further treatments in addition to radical surgery are required. Presurgical neoadjuvant cisplatin chemotherapy with methotrexate, vinblastine, doxorubicin and cisplatin (10) and gemicitabin plus cisplatin (11) have been demonstrated to improve the survival of patients with muscle invasive UCC. Immunohistochemical markers are useful for the prediction of cancer behavior and appropriate treatment choice and thus may contribute to improving patient survival. The cell cycle regulators, p53, retinoblastoma protein, p21, p27 and cyclin E1, have been reported to predict disease recurrence and mortality following radical cystectomy in patients with pTa-pT3 node-negative UCC (12). A combination of these markers exhibited significantly higher predictive accuracy for disease recurrence and cancer specific mortality compared with isolated use of the markers; however, the use of individual markers did not improve the predictive accuracy (12-14). Therefore, the identification of a novel marker that predicts survival of patients with aggressive UCC more accurately is urgently required.

The anaphylatoxin complement component 5 fragment a (C5a) is an $\mathrm{N}$-terminal 74-amino acid fragment that is released from the $\alpha$-chain of $\mathrm{C} 5$, which functions as a leukocyte chemoattractant and inflammatory mediator $(15,16)$. Increasing evidence has identified that the complement system is activated in human cancer tissues $(17,18)$ and in animal cancer models $(19,20)$, indicating that C5a may be present in the cancer microenvironment. $\mathrm{C} 5 \mathrm{a}$ functions by binding to the $\mathrm{C} 5 \mathrm{a}$ receptor $(\mathrm{C} 5 \mathrm{aR})$, which was originally identified in leukocyte cell lines (21). In our previous study, aberrant C5aR expression in cancer cells was identified in a number of different organs and C5a was demonstrated to enhance cancer cell invasiveness by activating motility and increasing matrix metalloproteinase release in a C5aR-dependent manner (22). Furthermore, direct $\mathrm{C} 5$ a release from $\mathrm{C} 5$ by cell membrane proteases of cancer cells and promotion of $\mathrm{C} 5 \mathrm{aR}$-expressing cancer cell invasiveness by C5a was demonstrated, indicating that a self-activation circuit via C5aR exists in cancer cells that express C5aR and proteases on the cell surface (23). Notably, a previous study revealed that a C5aR agonist increased cancer cell proliferation and C5aR silencing reduced tumor growth (24). Thus, we hypothesize that C5aR-positive cancer cells are more aggressive than C5aR-negative cells and thus, C5aR expression in cancer cells may be associated with poor prognosis of cancer patients.

To determine whether C5aR expression affects the prognosis of patients with aggressive UCC undergoing radical surgery, the association of UCC C5aR expression with clinicopathological parameters and survival outcomes of patients was evaluated.

\section{Materials and methods}

Patients and UCC samples. Cancerous and non-cancerous adjacent tissues were obtained from patients during surgery. A total of 52 patients with aggressive UCC who underwent radical cystectomy for bladder UCC (41 patients; 78\%) or radical nephroureterectomy for upper urinary tract UCC (11 patients; 22\%) at Kumamoto University Hospital (Kumamoto, Japan) between April 1996 and March 2013 were enrolled in the present study (Table I). The patient cohort included 39 male patients and 13 female patients with a median age of 72 years (range, $43-86$ years). The median duration of follow-up was 27.4 months (range, 0.53-150.0 months). A total of 16 patients (30.8\%) succumbed to urothelial cancer and 5 patients $(9.6 \%)$ succumbed due to other causes (4 pneumonitis; 1 unknown). Written informed consent for the use cancer and adjacent noncancerous tissues and clinicopathological records was obtained from all the patients prior to surgery. The Kumamoto University Hospital Ethics Committee approved the use of the samples and records for the present study.

Immunohistochemistry and retrospective analysis. Deparaffinized tissue sections $(2-\mu \mathrm{m})$ were pretreated with $0.3 \%$ $\mathrm{H}_{2} \mathrm{O}_{2}$ in methanol for $20 \mathrm{~min}$, followed by treatment with Protein Block Serum-Free (Dako Cytomation, Carpinteria, CA, USA) for $20 \mathrm{~min}$. Sections were incubated with primary mouse anti-human C5aR antibody ( $2 \mu \mathrm{g} / \mathrm{ml}$; dilution, 1:50; catalog no., HM2094; Hycult Biotech, Uden, The Netherlands) or nonspecific mouse $\operatorname{IgG}(2 \mu \mathrm{g} / \mathrm{ml}$; dilution, $1: 50$; catalog no., X0944; Dako Cytomation) at room temperature for $1 \mathrm{~h}$ followed by staining with EnVision+ solution (Dako Cytomation) and 3,3'-diaminobenzidine tetrahydrochloride solution (Wako Pure Chemical Industries, Ltd., Osaka, Japan) containing $0.006 \% \mathrm{H}_{2} \mathrm{O}_{2}$, according to the manufacturer's instructions. Nuclei were counterstained with hematoxylin (Kanto Chemical Co., Inc., Tokyo, Japan) and visualized with an optical microscope. Histopathological analyses were performed by senior pathologists and reviewed by the chief of clinical pathology. All tumors used in this study were classified as UCC according to the World Health Organization (WHO) grading criteria $(25,26)$. The association between UCC C5aR expression and patient survival, tumor stage and grade was analyzed. All the analyses were conducted by investigators blinded to the outcome of the patients.

Statistical analysis. In the analysis of clinicopathological parameters in association with UCC C5aR expression, Fisher's exact test was used, with the exception of age, which was analyzed with the Mann-Whitney U test. Kaplan-Meier analysis was performed to calculate 5-year survival rates and the log-rank test was conducted to analyze overall survival (OS). The Cox proportional hazards model was used to calculate the hazard ratio (HR) and $95 \%$ confidence interval (CI) for univariate and multivariate analysis. $\mathrm{P}<0.05$ was considered to indicate a statistically significant difference. All statistical analyses were performed using SPSS version 20.0 statistical software (IBM Corporation, Armonk, NY, USA).

\section{Results}

C5aR expression in UCC. C5aR expression was identified in 38 UCC patients (73\%) (Table I). C5aR staining (Fig. 1) was localized to the UCC cell membrane (Fig. 1A-C), however, no $\mathrm{C} 5 \mathrm{aR}$ expression was identified in noncancerous urothelial cells or adjacent cells (Fig. 1F). Notably, UCC cells at the invasive front rather than the surface layer expressed $\mathrm{C} 5 \mathrm{aR}$, and almost all UCC cells in the deeper invasion site were C5aR-positive (Fig. 1D and E). 
Table I. Association between C5aR expression and the clinicopathological parameters of 52 urothelial carcinoma cancer patients.

\begin{tabular}{|c|c|c|c|c|}
\hline Parameters & Patients, $\mathrm{n}^{\mathrm{a}}$ & C5aR $(+), \mathrm{n}$ & C5aR (-), n & P-value \\
\hline \multicolumn{5}{|l|}{ Age } \\
\hline Median, years (range) & 52 & $73.0(43-86)$ & $66.5(53-83)$ & $0.3640^{\mathrm{b}}$ \\
\hline \multicolumn{5}{|l|}{ Gender } \\
\hline Male & 39 & 28 & 11 & $0.5116^{\mathrm{c}}$ \\
\hline Female & 13 & 10 & 3 & \\
\hline \multicolumn{5}{|l|}{ Tumor location } \\
\hline Upper urinary tract & 11 & 7 & 4 & $0.3302^{\mathrm{c}}$ \\
\hline Bladder & 41 & 31 & 10 & \\
\hline \multicolumn{5}{|l|}{ WHO grade } \\
\hline G1-2 & 13 & 10 & 3 & $0.5047^{\mathrm{c}}$ \\
\hline G3 & 35 & 25 & 10 & \\
\hline \multicolumn{5}{|l|}{ T stage } \\
\hline $\mathrm{T} 1-2$ & 28 & 22 & 6 & $0.3659^{c}$ \\
\hline $\mathrm{T} 3-4$ & 20 & 14 & 6 & \\
\hline Blood vessel invasion, +/- & $19 / 26$ & $13 / 21$ & $6 / 5$ & $0.2726^{\mathrm{c}}$ \\
\hline Lymph node invasion, +/- & $19 / 28$ & $13 / 22$ & $6 / 6$ & $0.3265^{\mathrm{c}}$ \\
\hline \multicolumn{5}{|l|}{ Stage of disease } \\
\hline I-II & 24 & 20 & 4 & $0.1590^{\mathrm{c}}$ \\
\hline III-IV & 24 & 16 & 8 & \\
\hline
\end{tabular}

${ }^{a}$ Where the total number of patients does not equal 52, information concerning these parameters could not be obtained from certain patients. ${ }^{\text {b} P-v a l u e ~ d e t e r m i n e d ~ u s i n g ~ t h e ~ M a n n-W h i t n e y ~ U ~ t e s t . ~ ' P-v a l u e ~ d e t e r m i n e d ~ u s i n g ~ F i s h e r ' s ~ e x a c t ~ t e s t . ~(+), ~ p o s i t i v e ~ e x p r e s s i o n ; ~(-), ~ n e g a t i v e ~}$ expression; C5aR, complement component 5 fragment a receptor; WHO, World Health Organization.

Table II. Univariate and multivariate analysis of overall survival in 52 urothelial carcinoma patients.

\begin{tabular}{|c|c|c|c|c|c|c|c|}
\hline \multirow[b]{2}{*}{ Parameter } & \multirow{2}{*}{$\begin{array}{c}\text { 5-year } \\
\text { survival rate }\end{array}$} & \multicolumn{3}{|c|}{ Univariate analysis } & \multicolumn{3}{|c|}{ Multivariate analysis } \\
\hline & & HR & $95 \% \mathrm{CI}$ & P-value & HR & $95 \% \mathrm{CI}$ & P-value \\
\hline Location (PU/B) & $0.62 / 0.53$ & 1.89 & $0.56-6.45$ & 0.299 & 2.02 & $0.51-7.94$ & 0.313 \\
\hline C5aR expression (-/+) & $0.83 / 0.42$ & 3.14 & $1.03-9.60$ & 0.035 & 3.92 & $1.15-13.4$ & 0.029 \\
\hline WHO grade $(3 / 1-2)$ & $0.54 / 0.50$ & 1.04 & $0.38-2.88$ & 0.938 & 1.46 & $0.48-4.41$ & 0.508 \\
\hline Stage of disease (I-II/III-IV) & $0.64 / 0.43$ & 1.19 & $0.77-4.82$ & 0.156 & 2.30 & $0.86-6.16$ & 0.099 \\
\hline
\end{tabular}

Kaplan-Meier analysis method was used to calculate the 5-year survival rate. Cox proportional hazards regression was used to calculate the HR and 95\% CI. PU/B, pelvic vs. ureter/bladder; -/+, negative vs. positive; 3/1-2, 3 vs. 1 and 2; 1-2/3-4; I and II vs. III and IV; HR, hazard ratio; $\mathrm{CI}$, confidence interval; WHO, World Health Organization.

Association between UCC C5aR expression and clinicopathological parameters. The associations between clinicopathological parameters and C5aR expression were investigated (Table I). Previously, age was demonstrated as a risk factor for developing UCC of the bladder and advanced bladder UCC is more common in females who exhibit worse survival rates than males (27). Since there was no significant association of UCC C5aR expression with age and gender in the present study, the two parameters are unlikely to show bias towards the low overall survival rate of patients with C5aR-positive UCC. No significant differences in C5aR expression were identified between different UCC locations, including the bladder and upper urinary tract. Furthermore, UCC C5aR expression was not associated with tumor grade, pathological tumor stage, vessel invasion or clinical stage; however, it is notable that UCC C5aR-positive rate was markedly high in tumors at T1-2 and of patients at stage I-II.

Association between UCC C5aR expression and patient survival. To determine whether C5aR expression correlated with UCC patient prognosis, patient survival times were investigated. No significant differences in 5-year survival rate and OS rate were identified between UCC of the upper (pelvic/ureter) and lower (bladder) urinary tract (Table II), 


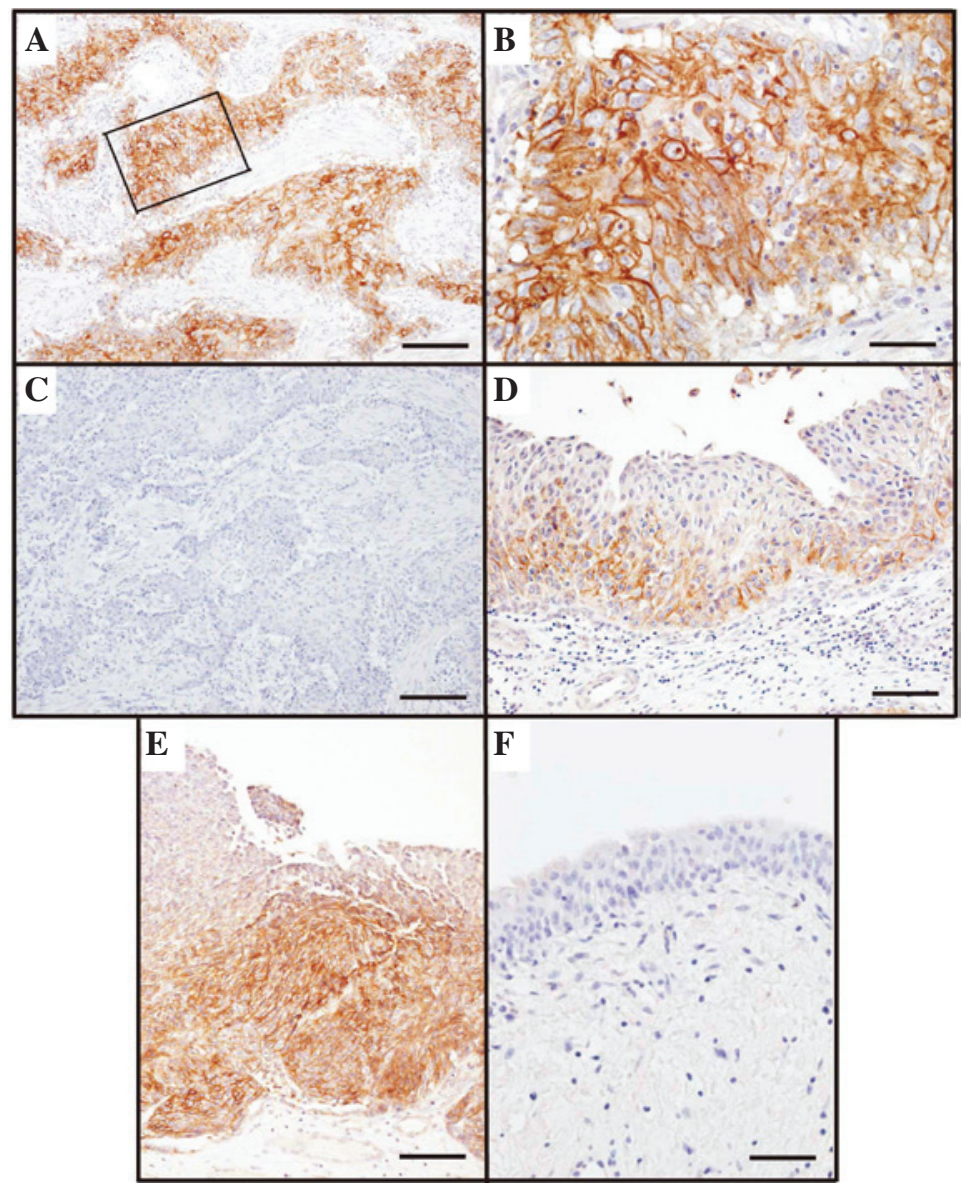

Figure 1. Immunohistochemical staining of UCC tissues for C5aR. Tissue sections were immunostained with anti-human C5aR IgG antibodies. (A) UCC tissue in the deep invasion site; scale bar, $200 \mu \mathrm{m}$. (B) Magnified UCC tissue surrounded by the square in part A; scale bar, 50 $\mu \mathrm{m}$. (C) Same UCC tissue stained with nonspecific IgG; scale bar, $200 \mu \mathrm{m}$. (D) UCC localized in the surface area; scale bar, $100 \mu \mathrm{m}$. (E) UCC of advanced invasion; scale bar, $100 \mu \mathrm{m}$. (F) Noncancerous urothelial cell layer; scale bar, 50 $\mu \mathrm{m}$. UCC, urothelial cell carcinoma; C5aR, C5a receptor; IgG, immunoglobulin G.

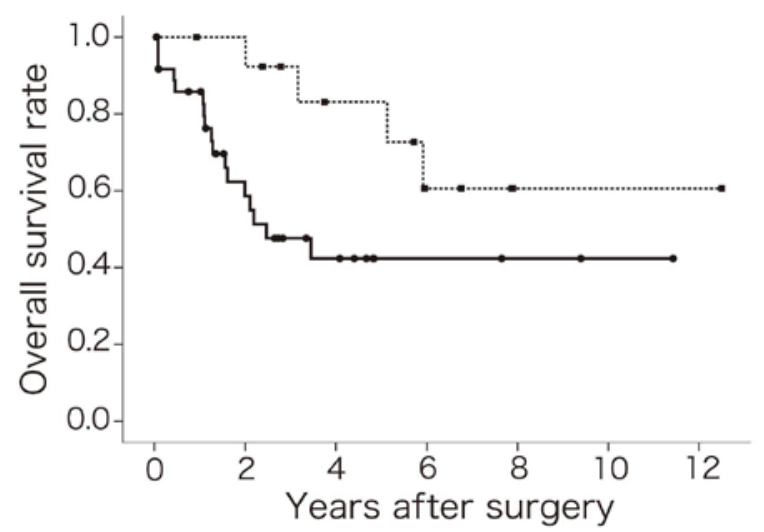

Figure 2. Overall survival rates of patients with C5aR-positive (solid line) and C5aR-negative (dashed line) UCC. C5aR, complement component 5 fragment a receptor; UCC, urothelial cell carcinoma.

which enabled survival rate analysis to be conducted for all patients in this study. The OS rate of C5aR-positive UCC patients was lower than that of C5aR-negative patients (Fig. 2). Furthermore, the 5-year survival rate of C5aR-positive UCC patients was $\sim 50 \%$ lower compared with C5aR-negative UCC patients (Table II). Univariate (HR, 3.14; $\mathrm{P}=0.035)$ and multivariate $(\mathrm{HR}, 3.92 ; \mathrm{P}=0.029)$ analyses revealed that the $\mathrm{OS}$ rate of patients with C5aR-positive UCC was significantly lower than that of patients with C5aR-negative UCC. However, no significant differences in OS rate were identified between UCC WHO grade or stage of disease (Table II). Furthermore, UCC $\mathrm{C} 5 \mathrm{aR}$ expression was not associated with the disease-specific survival rate of patients $(\mathrm{P}=0.092)$; however, the diseasespecific 5-year survival rate was significantly lower in patients with C5aR-positive UCC $(0.51 ; 95 \%$ CI, 0.30-0.71) than patients with C5aR-negative UCC $(0.83 ; 95 \%$ CI, 0.62-1.00) $(\mathrm{P}=0.032)$.

\section{Discussion}

The present study identified that $\mathrm{C} 5 \mathrm{aR}$ is expressed in aggressive type UCC cells and revealed that patients with C5aR-positive UCC exhibit lower survival rates when compared with C5aR-negative UCC patients. Aggressive type UCC cells expressed $\mathrm{C} 5 \mathrm{aR}$ at the greatest rate $(73 \%)$ (Fig. 1; Table I) compared with the C5aR-positive rates of other types of cancer, as previously reported (22). This finding may indicate an association between $\mathrm{C} 5 \mathrm{aR}$ expression and UCC aggressiveness. Invasiveness of C5aR-expressing cancer cells is augmented by C5a (22), which is present in the cancer microenvironment (17-20). UCC cells at the invasive front are in direct contact with interstitial fluid that contains $\mathrm{C} 5$, which 
facilitates C5a release by cancer cell proteases (23). C5aR expression in UCC cells at the invasive front (Fig. 1D and E) appears to be correlated with the invasiveness of aggressive UCC (3). Thus, the poor outcomes of patients with C5aR-positive UCC (Fig. 2; Table II) may be associated with the invasive potential of C5a-activated C5aR-positive cancer cells (22).

Pathological factors have been widely used to predict the outcomes of patients with cancer, including UCC. In UCC, advanced tumor stage and grade are associated with distant metastasis and increased invasive potential (28). In addition, tumor size (diameter $\geq 3 \mathrm{~cm}$ ) and lymph node invasion indicate a worse prognosis for UCC patients $(29,30)$. However, $20 \%$ of aggressive UCC patients that undergo total cystectomy experience recurrence (4) and the survival rate of UCC patients that undergo total nephroureterectomy is relatively low ( 60\%) (7). These studies indicate the limited efficacy of radical surgeries and highlight the urgent requirement for other reliable prognostic/predictive markers to identify patients that require additional treatments to decrease the risk of cancer recurrence and mortality. In the present study, C5aR expression was identified as a possible negative prognostic factor for aggressive UCC (Table II). In this study, C5aR-expressing UCC patients exhibited the shortest OS times and the highest HRs, which may indicate that disease-associated mortality is more closely correlated with C5aR expression than high cancer grade or advanced clinical stage. In addition, no significant associations were identified between UCC C5aR expression and negative prognostic factors, including tumor grade and stage, vessel invasion or clinical stage (Table I). Multivariate analysis revealed that C5aR-positive UCC patients exhibited a significantly lower OS rate than C5aR-negative UCC patients (Table II). Therefore, these results indicate that C5aR expression is an independent prognostic factor of poor outcomes for UCC patients.

A previous study demonstrated a synergistic effect of the apoptosis markers, $\mathrm{Bcl}-2$, caspase-3, p53 and survivin, on the progression of bladder cancer and revealed that changes in the expression of the four markers in patients that underwent radical cystectomy was independently predictive of high risk for disease recurrence and mortality (31). Although it has not yet been demonstrated in human UCC, C5aR signaling suppresses apoptosis, induces T-cell expansion via the enhanced expression of Bcl-2 (32) and enhances neuronal cell survival via inhibition of caspase-3 activation (33). C5a is present in the cancer microenvironment $(17,20,23)$, where, by stimulation with $\mathrm{C} 5 \mathrm{a}$, the apoptosis of $\mathrm{C} 5 \mathrm{aR}$-expressing UCC may be suppressed; this supression facilitates the growth and development of cancer in concert with the C5a-elicited enhancement of proliferation (24) and invasiveness (22). Thus, C5aR expression in UCC may correlate with the low survival rate exhibited by patients (Table II). It has been reported that high C5aR mRNA expression in cancer cells is associated with short survival time in patients with ovarian or lung cancer (24), in accordance with the results of the present study, which revealed that $\mathrm{C} 5 \mathrm{aR}$ protein expression of UCC cells correlated with low survival rates in UCC patients (Fig. 2; Table II). These results indicate that cancer cell C5aR expression is a marker of poor prognosis.

In bladder cancer patients that underwent radical cystectomy, survivin overexpression was demonstrated to be associated with increased overall mortality, cancer specific mortality and tumor recurrence (34). However, increased survivin expression was also associated with advanced pathological stage, lymphovascular invasion and lymph node metastasis, which indicates that survivin expression is lower at the early stages of UCC than the advanced stages. By contrast, higher C5aR expression at organ-confined cancer stages, T1 and $\mathrm{T} 2$, and higher HR of C5aR expression as an independent prognostic factor of poor outcomes (Tables I and II), indicates that UCC C5aR expression may lead to the use of additional treatments at relatively early stages of disease for patients undergoing surgery. Since C5aR-positive UCC patients exhibit a lower disease-specific 5-year survival rate than C5aR-negative UCC patients, additional treatments at the earlier stages of disease may improve prognosis. Further study is required to establish an association between UCC C5aR expression and clinical outcomes, including cancer recurrence, progression and mortality, for early stage UCC patients with C5aR-positive cells in the urine or tissues obtained from transurethral resection or bladder tumor biopsy.

In conclusion, UCC C5aR expression was identified as an independent marker of poor prognosis in aggressive UCC in the present study. Notably, C5aR expression is higher at earlier stages of UCC and thus, immunohistochemical staining of $\mathrm{C} 5 \mathrm{aR}$ in UCC may be applicable for clinical examination (cytological analysis of urine and/or biopsied tissues), to provide information regarding tumor aggressiveness. This information may also be used to predict the prognosis of UCC patients. Future studies that evaluate the efficacy of additional treatments, such as adjuvant chemotherapy, radiotherapy and/or molecular-targeted therapy, for the prevention of recurrence and improvement of survival outcomes in C5aR-positive UCC patients are required.

\section{Acknowledgements}

This study was partially supported by The Japanese Science Progress Society (grant no's. 22590363 and 25460498).

\section{References}

1. Siegel R, Naishadham MA and Jemal A: Cancer statistics, 2013. CA Cancer J Clin 63: 11-30, 2013.

2. Knowles MA: Molecular subtypes of bladder cancer: Jekyll and Hyde or chalk and cheese? Carcinogenesis 27: 361-373, 2006.

3. Stein JP, Lieskovsky G, Cote R, Groshen S, Feng AC, Boyd S, Skinner E, Bochner B, Thangathurai D, Mikhail M, et al: Radical cystectomy in the treatment of invasive bladder cancer: Long-term results in 1,054 patients. J Clin Oncol 19: 666-675, 2001.

4. Hautmann RE, Gschwend JE, de Petriconi RC, Kron M and Volkmer BG: Cystectomy for transitional cell carcinoma of the bladder: Results of a surgery only series in the neobaldder era. J Urol 176: 486-492, 2006.

5. Shariat SF, Karakiewicz PI, Palapattu GS, Lotan Y, Rogers CG, Amiel GE, Vazina A, Gupta A, Bastian PJ, Sagalowsky AI, et al: Outcomes of radical cystectomy for transitional cell carcinoma of the bladder: A comtemporary series from the Bladder Cancer Research Consortium. J Urol 176: 2414-2422, 2006.

6. Dinney CP, McConkey DJ, Millikan RE, Wu X, Bar-Eli M, Adam L, Kamat AM, Siefker-Radtke AO, Tuziak T, Sabichi AL, et al: Focus on bladder cancer. Cancer Cell 6: 111-116, 2004.

7. Kobayashi Y, Saika T, Manabe D, Nasu Y and Kumon H: Prognostic factors influencing survival after nephroureterectomy for transitional cell carcinoma of the upper urinary tract. Acta Med Okayama 65: 143-149, 2011. 
8. Hall MC, Womack S, Sagalowsky AI, Carmody T, Erickstad MD and Roehrborn CG: Prognostic factors, recurrence, and survival in transitional cell cartinoma of the upper tract: A 30-year experience in 252 patients. Urology 52: 594-601, 1998.

9. Casey RG, Catto JWF, Cheng L, Cookson MS, Herr H, Shariat S, Witjes JA and Black PC: Diagnosis and management of urothelial carcinoma in situ of the lower urinary tract: A systematic review. Eur Urol 67: 876-888, 2015.

10. Grossman HB, Natale RB, Tangen CM, Speights VO, Vogelzang NJ, Trump DL, deVere White RW, Sarosdy MF, Wood DP Jr, Raghavan D and Crawford ED: Neoadjuvant chemotherapy plus cystectomy compared with cystectomy alone for locally advanced bladder cancer. N Engl J Med 349: 859-866, 2003.

11. von der Maase H, Hansen SW, Roberts JT, Dogliotti L, Oliver T, Moore MJ, Bodrogi I, Albers P, Knuth A, Lippert CM, et al: Gemcitabine and cisplatin versus methotrexate, vinblastine, doxorubicin, and cisplatin in advanced or metastatic bladder cancer: Results of a large, randomized, multinational, multicenter, phase III study. J Clin Oncol 18: 3068-3077, 2000.

12. Shariat SF, Karakiewicz PI, Ashfaq R, Lerner SP, Palapattu GS, Cote RJ, Sagalowsky AI and Lotan Y: Multiple biomarkers improve prediction of bladder cancer recurrence and mortality in patients undergoing cystectomy. Cancer 112: 315-325, 2008.

13. Shariat SF, Zlotta AR, Ashfaq R, Sagalowsky AI and Lotan Y: Cooperative effect of cell-cycle regulators expression on bladder cancer development and biological aggressiveness. Mod Pathol 20: 445-459, 2007.

14. Shariat SF, Chade DC, Karakiewicz PI, Ashfaq R, Isbarn H, Fradet Y, Bastian PJ, Nielsen ME, Capitanio U, Jeldres C, et al: Combination of multiple markers can improve prognostication in patients with locally advanced and lymph node positive bladder cancer. J Urol 183: 68-75, 2010.

15. Guo RF and Ward PA: Role of C5a in inflammatory responses. Annu Rev Immunol 23: 821-852, 2005.

16. Markiewski MM and Lambris JD: The role of complement in inflammatory diseases from behind the scenes into the spotlight Am J Pathol 171: 715-727, 2007.

17. Niculescu F, Rus HG, Retegan M and Vlaicu R: Persistent complement activation on tumor cells in breast cancer. Am J Pathol 140: 1039-1043, 1992.

18. Bjørge L, Hakulinen J, Vintermyr OK, Jarva H, Jensen TS, Iversen $\mathrm{OE}$ and Meri S: Ascitic complement system in ovarian cancer. Br J Cancer 92: 895-905, 2005.

19. Markiewski MM, DeAngelis RA, Benencia F, Ricklin-Lichtsteiner SK, Koutoulaki A, Gerard C, Coukos G and Lambris JD Modulation of the antitumor immune response by complement Nat Immunol 9: 1225-1235, 2008.

20. Corrales L, Ajona D, Rafail S, Lasarte JJ, Riezu-Boj JI, Lambris JD, Rouzaut A, Pajares MJ, Montuenga LM and Pio R: Anaphylatoxin C5a creates a favorable microenvironment for lung cancer progression. J Immunol 189: 4674-4683, 2012.

21. Gerard NP and Gerard C: The chemotactic receptor for human C5a anaphylatoxin. Nature 349: 614-617, 1991.
22. Nitta H, Wada Y, Kawano Y, Murakami Y, Irie A, Taniguchi K, Kikuchi K, Yamada G, Suzuki K, Honda J, et al: Enhancement of human cancer cell motility and invasiveness by anaphylatoxin C5a via aberrantly expressed C5a receptor (CD88). Clin Cancer Res 19: 2004-2013, 2013.

23. Nitta H, Murakami Y, Wada Y, Eto M, Baba H and Imamura T: Cancer cells release anaphylatoxin C5a from C5 by serine protease to enhance invasiveness. Oncol Rep 32: 1715-1719, 2014.

24. Cho MS, Vasquez HG, Rupaimoole R, Pradeep S, Wu S, Zand B, Han HD, Rodriguez-Aguayo C, Bottsford-Miller J, Huang $\mathrm{J}$, et al: Autocrine effects of tumor-derived complement. Cell Rep 6: 1085-1095, 2014.

25. Eble JN, Sauter G, Epstein JI and Sesterhenn IA (eds): World Health Organization Classification of Tumours. Pathology and Genetics of Tumours of the Urinary System and Male Genital Organs. IARC Press, Lyon, 2004.

26. Mostofi FK, Sobin LH and Torloni H (eds): Histological typing of urinary bladder tumours. International Classification of Tumours 10. World Health Organization, Geneva, 1973

27. Shariat SF, Sfakianos JP, Droller MJ, Karakiewicz PI, Meryn S and Bochner BH: The effect of age and gender on bladder cancer: A critical review of the literature. BJU Int 105: 300-308, 2010.

28. Lughezzani G, Burger M, Margulis V, Matin SF, Novara G, Roupret M, Shariat SF, Wood CG and Zigeuner R: Prognostic factors in upper urinary tract urothelial carcinomas: A comprehensive review of the current literature. Eur Urol 62: 100-114, 2012.

29. Simone G, Papalia R, Loreto A, Leonardo C, Sentinelli S and Gallucci M: Independent prognostic value of tumour diameter and tumournecrosis in upper urinary tract urothelial carcinoma. BJU Int 103: 1052-1057, 2009.

30. Kikuchi E, Margulis V, Karakiewicz PI, Roscigno M, Mikami S, Lotan Y, Remzi M, Bolenz C, Langner C, Weizer A, et al: Lymphovascular invasion predicts clinical outcomes in patients with node-negative upper tract urothelial carcinoma. J Clin Oncol 27: 612-618, 2009.

31. Karam JA, Lotan Y, Karakiewicz PI, Ashfaq R, Sagalowsky AI, Roehrborn CG and Shariat SF: Use of combined apoptosis biomarkers for predicition of bladder cancer recurrence and mortality after radical cystectomy. Lancet Oncol 8: 128-136, 2007.

32. Lalli PN, Strainic MG, Yang M, Lin F, Medof ME and Heeger PS: Locally produced C5a binds to T cell-expressed C5aR to enhance effector T-cell expansion by limiting antigen-induced apoptosis. Blood 112: 1759-1766, 2008.

33. Bénard M, Gonzalez BJ, Schouft MT, Falluel-Morel A, Vaudry D, Chan P, Vaudry H and Fontaine M: Characterization of C3a and C5a receptors in rat cellebellar granule neurons during maturation. Neuroprotective effect of C5a against apoptotic cell death. J Biol Chem 279: 43487-43496, 2004.

34. Shariat SF, Ashfaq R, Karakiewicz PI, Saeedi O, Sagalowsky AI and Lotan Y: Survivin expression is associated with bladder cancer presence, stage, progression and mortality. Cancer 109: 1106-1113, 2007. 